\title{
Esmolol for the treatment of refractory ventricular fibrillation: A systematic review and meta- analysis
}

Armour, Richard and Baranowski, Leon

Accepted for publication in Irish Journal of Paramedicine, Vol 4, Issue 2. This is the accepted version of the article, post peer-review. A final publisher version will be provided in due course.

Introduction: In light of recent research the efficacy of current advanced life support treatments has been questioned. Ventricular fibrillation refractory to standard therapy is a presentation which may benefit from an updated approach to management, with the $\beta_{1}$-adrenoreceptor antagonist esmolol considered a therapy which may confer benefit. This systematic review and meta-analysis aimed to summarise the available evidence for esmolol in refractory ventricular fibrillation and identify if it may have any role in ACLS guidelines.

Methods: The Cochrane Library, MEDLINE, CINAHL and EMBASE were systematically reviewed, along with trial registries and the grey literature. Studies were included in the review and subsequent meta-analysis if they examined adult patients in cardiopulmonary arrest with ventricular fibrillation refractory to at least three attempts at defibrillation and one dose of adrenaline or anti-arrhythmic therapy, who subsequently received intravenous esmolol.

Results: 2,617 results were obtained with 12 full-text articles reviewed for inclusion. Ultimately, two unique results fulfilled the inclusion criteria. A total of 66 patients were included in the meta-analysis, of whom 22 received esmolol. Esmolol appears to improve to survival to hospital admission (RR 2.63, 95\% 
CI 1.37-5.07, $\mathrm{p}=0.004)$, temporary $(\mathrm{RR} 2.34,95 \% \mathrm{CI} 1.09-5.02, \mathrm{p}=0.03)$ and sustained ROSC $(\mathrm{RR} 2.63$, 95\% CI 1.37-5.07, $\mathrm{p}=0.004$ ) and favourable neurological status at hospital discharge (RR 3.44, 95\% CI 1.11-10.67, $\mathrm{p}=0.03)$. The use of esmolol also appeared to likely confer a benefit in survival to hospital discharge (RR 2.82, 95\% CI 1.01-7.93, p=0.05). However, significant bias was observed across all outcomes and overall these results were considered to be of low to very low certainty.

Conclusion: The use of esmolol in refractory ventricular fibrillation appears to improve survival to hospital admission, temporary and sustained ROSC and neurological status at hospital discharge, but not survival to hospital discharge. However, these results should be interpreted with caution in light of the limitations of included studies and the subsequent impact of these limitations on the outcomes included in the meta-analysis. Further high-quality, prospective research is required prior to recommending esmolol for use in refractory ventricular fibrillation.

Keywords: Cardiac Arrest, Ventricular Fibrillation, Cardiac Arrest, Out of Hospital, Esmolol 


\section{Introduction}

Sudden Cardiopulmonary Arrest (SCA) is the cessation of spontaneous respirations and cardiac activity, resulting in a rapid loss of perfusion and without treatment, death $(1,2)$. SCA frequently occurs in an emergency setting, whether out-of-hospital (OHSCA) or in the emergency department, requiring intervention from pre-hospital and emergency clinicians (3). In the United Kingdom (UK) ambulance services attempt resuscitation in approximately 30,000 cases of OHSCA annually (4), in Canada 35,000 (5), in Australia 15,000 (6) and in the United States of America (USA) 356,000 (7). Despite the extensive efforts of both pre-hospital and emergency clinicians, survival from OHSCA remains low at 5-12\% depending on geographic region (4-7). Survival and neurological status post-resuscitation in SCA and OHSCA is most heavily associated with the immediate provision of Basic Life Support (BLS) interventions by bystanders or clinicians, including early chest compressions and defibrillation (8-10). However, some cases of SCA will not resolve with these initial measures.

In cases of SCA unresponsive to BLS interventions, Advanced Cardiac Life Support (ACLS) is initiated. Traditionally, this has included the provision of advanced airway management in the form of endotracheal intubation or supraglottic airway placement as well as the commencement of pharmacological therapies such as epinephrine, amiodarone and lidocaine. However, recent research such as AIRWAYS-2 (11), PARAMEDIC-2 (12) and ALPS (13), amongst others $(14,15)$, has raised questions regarding the efficacy of current recommended ACLS therapies. Given the plethora of underlying physiological states which may precipitate SCA (2), an individualised approach to the management of SCA has been advocated, as opposed to the didactic approach recommended by many ACLS algorithms. Ventricular Fibrillation (VF) refractory to initial defibrillation attempts is one such presentation of SCA which is hypothesised to likely benefit from a unique, tailored management strategy. 
VF is a commonly reported arrhythmia in SCA and $\operatorname{OHSCA}(16,17)$ and is generally classed as refractory when unresponsive to at least three consecutive attempts at defibrillation and initial antiarrhythmic therapy (18-20), although some literature suggests 10-minutes of consecutive resuscitation without conversion from VF refractory $(21,22)$. Refractory VF (rVF) results in a large surge of endogenous sympathetic hormones (epinephrine and norepinephrine) $(23,24)$, which is compounded by the administration of high-dose adrenaline in ACLS care. The excessive levels of circulating catecholamines cause a dramatic increase in myocardial oxygen demand through positive chronotropy and inotropy $(25,26)$, as well as over stimulation of $\beta$-adrenoreceptors, particularly $\beta_{1}$-adrenoreceptors (25-26). Excessive activation of $\beta_{1}$-adrenoreceptors causes an increase in calcium influx into myocardial cells (27). This action, in conjunction with a continually rising myocardial oxygen demand, conspire to reduce the likelihood of successful attempts at defibrillation $(23-24,28)$. The use of Double Sequential Defibrillation (DSD) or intravenous $\beta$-antagonists has been hypothesised to improve the likelihood of successful defibrillation in $\operatorname{rVF}(19,29-33)$. However, a recent meta-analysis found no evidence of benefit for DSD in rVF (34) and a meta-analysis performed in 2012 found insufficient evidence to provide firm recommendations regarding $\beta$-antagonist use, although a trend towards benefit was observed (33).

Since the completion of the meta-analysis investigating $\beta$-antagonists (33) esmolol has emerged as the $\beta$ antagonist potentially most appropriate for use in SCA, owing to its selective $\beta_{1}$-adrenoreceptor antagonism and rapid onset of action $(33,35)$. In animal models of SCA the use of esmolol has been shown to blunt the effects of the sympathetic surge in $\mathrm{rVF}$, resulting in improved rates of resuscitation (36-37), reduced energy requirements for defibrillation (36-37), improved cardiovascular stability postresuscitation (37-38) and better short-term survival (37-38). However, definitive guidance on the use of esmolol in human SCA is lacking. This systematic review and meta-analysis aimed to summarise the 
available evidence for the use of esmolol in cases of rVF and identify if it may have a role in ACLS guidelines.

\section{Objectives}

This systematic review and meta-analysis aimed to determine whether the addition of intravenous esmolol, as an initial bolus dose with subsequent infusion, to standard ACLS care provided to patients in rVF:

- Impacts patient survival to hospital admission

- Impacts patient survival to hospital discharge

- Impacts patient neurological status at hospital discharge

- Influences the rate of return of spontaneous circulation in this group

\section{Methods}

This systematic review and meta-analysis were performed and reported in accordance with the Preferred Reporting Items for Systematic Reviews and Meta-Analysis (PRISMA) guideline (Supplementary File).

\section{Study Types for Inclusion}

Randomised controlled trials, non-randomised controlled trials and cohort studies were preferentially sought for inclusion in this review and meta-analysis. However, given the limited results fulfilling these criteria case-control series were also subsequently considered for inclusion in this review.

\section{Population Examined}

Adult patients (18 years of age or over) in cardiopulmonary arrest in the out-of-hospital or emergency setting with a presenting rhythm of ventricular fibrillation refractory to standard ACLS therapy, defined 
as a minimum of three attempts at defibrillation and at least one dose of intravenous epinephrine and/or anti-arrhythmic therapy.

\section{Intervention and Comparison}

The intervention examined was intravenous esmolol at an initial bolus dose of $500 \mathrm{mcg} / \mathrm{kg}$, followed by an infusion of up to $100 \mathrm{mcg} / \mathrm{kg} / \mathrm{min}$. Patients receiving this therapy were compared against patients who did not receive intravenous esmolol as part of their ongoing resuscitative efforts and had received a minimum of three attempts at defibrillation and at least one dose of intravenous adrenaline or anti-arrhythmic therapy.

\section{Primary Outcome Measure}

Patient survival to hospital admission.

\section{Secondary Outcome Measures}

Return of Spontaneous Circulation, patient survival to hospital discharge and patient neurological status at hospital discharge (measured with the Cerebral Performance Category Score, with scores of one or two considered favourable).

\section{Figure 1: Cerebral Performance Categories Scale (39)}

CPC 1 Good cerebral performance: conscious, alert, able to work and may have mild neurologic or psychologic deficit

CPC 2 Moderate cerebral disability: conscious, sufficient cerebral function for independent activities of daily life and able to work in sheltered environment

CPC 3 Severe cerebral disability: conscious, dependent on others for daily support because of impaired brain function

CPC 4 Coma or vegetative state: any degree of coma without the presence of all brain death criteria

CPC 5 Brain death: apnoea, areflexia, EEG silence 


\section{Search Strategies (Supplementary File)}

In order to ensure potential evidence was obtained from both the fields of emergency and pre-hospital medicine a number of electronic databases were searched from their date of inception until November 2018, including The Cochrane Library, MEDLINE, EMBASE and CINAHL (Supplemental File). Search strategies were not limited by language, publication status or date. The ISRCTN Registry of Controlled Trials, the WHO International Clinical Trials Registry Platform, Health Canada's Clinical Trials Registry and the United States National Library of Medicine Clinical Trial Registry were also searched for ongoing clinical trials into the use of esmolol in rVF. Scopus and EMBASE were utilised to scan conference proceedings for potential unpublished literature or literature currently under review. Google Scholar and Open Grey Europe were utilised to scan for any further grey literature related to esmolol in rVF. Citations from retrieved results were also inspected for results not obtained utilising the search strategy or in the analysis of the grey literature.

\section{Selection of Studies}

In determining the eligibility of retrieved studies for inclusion in this systematic review and metaanalysis, both authors performed a preliminary analysis of the title and abstract of each retrieved result from the electronic databases and grey literature. The pre-defined inclusion criteria were applied to the retrieved results and where doubt existed, the full-text was retrieved for assessment of possible inclusion. If further uncertainty existed, an agreement was reached between authors.

\section{Assessment of Methodological Quality}

The assessment of methodological quality was performed by both authors, blinded to the others' verdict, employing previously validated checklists for assessment of study rigor.

- Randomised Controlled Trials were assessed using the CASP Checklist for Randomised Controlled Trials (40) 
- Cohort Studies were assessed using the CASP Checklist for Cohort Studies (41)

- Case-Control Series were assessed using the Joanna Briggs Institute Checklist for Case-Control Series (42)

\section{Data Extraction}

Both authors extracted data from results meeting the inclusion criteria utilising a standardised data extraction form. Data was pre-defined for extraction and is summarised in Table 1. Where uncertainty existed regarding any data extracted from eligible results, the data extraction performed by each author were compared to ensure complete analysis. If data was unclear, lead authors from eligible studies were contacted for clarification.

\begin{tabular}{|c|c|}
\hline Patient Population & $\begin{array}{ll}\text { - } & \text { Age } \\
\text { - } & \text { Sex } \\
\text { - } & \text { Co-morbidities present }\end{array}$ \\
\hline $\begin{array}{l}\text { Cardiac Arrest } \\
\text { Characteristics }\end{array}$ & $\begin{array}{l}\text { - Witnessed compared with } \\
\text { - Unwitnessed } \\
\text { - Bystander CPR provided } \\
\text { - Suspected aetiology }\end{array}$ \\
\hline $\begin{array}{l}\text { Standard Therapy } \\
\text { Provided }\end{array}$ & $\begin{array}{l}\text { - } \text { Defibrillation } \\
\text { - } \text { Epinephrine } \\
\text { - } \text { Amiodarone } \\
\text { - } \text { Lidocaine } \\
\text { - } \text { Other non-specified }\end{array}$ \\
\hline $\begin{array}{l}\text { Intervention } \\
\text { Characteristics }\end{array}$ & $\begin{array}{l}\text { - } \quad \text { Timing of Esmolol } \\
\text { - } \quad \text { Dosage of Esmolol }\end{array}$ \\
\hline Outcome Measures & $\begin{array}{l}\text { - } \quad \text { Measures utilised } \\
\text { - } \quad \text { Timing of outcome } \\
\text { assessment }\end{array}$ \\
\hline
\end{tabular}




\section{Assessment of Risk of Bias}

Both authors assessed the risk of bias at the study level utilising the Cochrane Collaboration's Tool for Assessing Risk of Bias in randomised studies and using the ROBINS-I Tool in non-randomised studies. When assessing the risk of bias across outcomes and the certainty of evidence the Grading of Recommendations Assessment, Development and Evaluation (GRADE) approach was utilised. Where uncertainty existed agreement was reached between authors.

\section{Synthesis of Results}

Data collected was placed in a single spreadsheet for ease of access, with results combined using the RevMan 5.3 Software and presented in a GRADE Evidence Profile table graciously provided by GRADEpro on a student license. A random-effects model of meta-analysis was utilised, with a risk-ratio chosen for the presentation of results. A risk-ratio was chosen as although the overall survival from OHSCA is $5-12 \%$, survival in cases of VF is commonly reported as greater than $10 \%$ (42). Outcomes which occur at a rate of $10 \%$ or higher are often exaggerated by odds-ratios, with risk-ratios also easier to apply to clinical practice (43). Heterogeneity was assessed utilising the $\mathrm{I}^{2}$ statistic.

\section{Results}

\section{Study Selection}

The search strategies retrieved 17 results from The Cochrane Library, 24 results from CINAHL, 362 results from MEDLINE and 2,200 results from EMBASE. After removal of duplicates and screening of abstracts 12 full-text articles were assessed for inclusion. Two full-text articles ultimately fulfilled the pre-defined inclusion criteria. Searching the grey literature, unpublished literature and conference abstracts yielded two abstracts potentially relevant to this systematic review and meta-analysis, however, 
no contact information was provided for these abstracts and the results appeared to primarily relate to clinical settings outside SCA.

Figure 2: Study Selection Flow

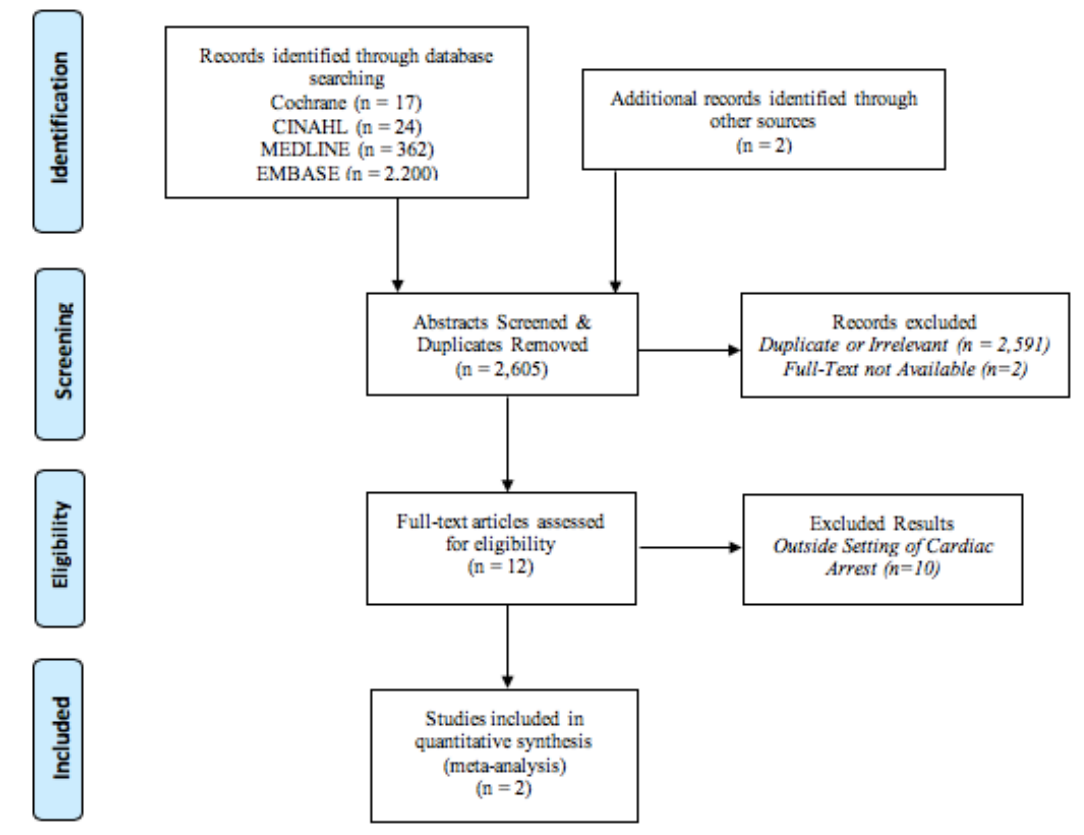

\section{Study Characteristics}

No randomised or non-randomised controlled trials were identified in the systematic review, with the two studies identified both retrospective cohort studies. One study was conducted in the USA by Driver et al (44), whilst the other was conducted in South Korea by Lee et al (45). The combined studies included a total of 66 patients, of whom 22 received esmolol and 44 did not. Patients were overwhelmingly male $(\mathrm{n}=57 / 66)$ with the median age ranging from 52 to 58 between treatment groups. The pre-morbid state of patients was poorly described by both authors, with Driver et al providing information regarding the premorbid state of only those patients receiving esmolol and Lee et al providing no information $(44,45)$. 
The majority of SCAs were witnessed events $(n=52 / 66)$ and were largely the result of cardiac pathology $(n=42 / 66)$. Bystander chest compressions $(\mathrm{CC})$ were provided in 47 cases $(71 \%)$, a rate higher than the North American average of $46 \%$ (46). In Driver et al, interventional patients received a median of 6.5 attempts at defibrillation (IQR 5-9.5) compared with control patients who had a median of 7 attempts (IQR 5-8) (44). This was contrasted in Lee et al, where patients receiving esmolol had a median of 6 attempts at defibrillation (IQR 6-8.75), whilst control patients received a median of 5 attempts (IQR 5$6.5)(45)$.

Table 2: Study Characteristics \& Retrieved Data

Values reported as Medians with Interquartile Ranges, where appropriate

\begin{tabular}{|c|c|c|c|c|}
\hline Study & Driver et al 201 & $4^{44}$ & Lee et al 2016 & \\
\hline Group & Esmolol & No Esmolol & Esmolol & No Esmolol \\
\hline Age & $54.5(47-59)$ & $56(48-66)$ & $58(43.5-72)$ & $52(43.5-64.5)$ \\
\hline Male (\%) & $6(100)$ & $18(95)$ & $14(87.5)$ & $19(76)$ \\
\hline Witnessed (\%) & $5(83)$ & $16(84)$ & $14(87.5)$ & $17(68)$ \\
\hline $\begin{array}{l}\text { Bystander CPR Provided } \\
(\%)\end{array}$ & $3(75)$ & $14(78)$ & $11(69)$ & $16(64)$ \\
\hline $\begin{array}{l}\text { Suspected Cardiac Aetiology } \\
(\%)\end{array}$ & $2(33 \%)$ & Not Described & $15(94)$ & $23(92)$ \\
\hline Defibrillation & $6.5(5-9.5)$ & $7(5-8)$ & $6(6-8.75)$ & $5(5-6.5)$ \\
\hline Epinephrine (mg) & $6(5-7.75)$ & $6(5-7)$ & $6(3.3-9)$ & $6(5-8)$ \\
\hline Amiodarone (mg) & $375(300-450)$ & $450(300-450)$ & $450(300-450)$ & $300(300-450)$ \\
\hline Sodium Bicarbonate (mEq) & $\begin{array}{l}225(200- \\
287.5)\end{array}$ & $150(100-250)$ & $0(0-40)$ & $0(0-160)$ \\
\hline Timing of Esmolol (minutes) & $\begin{array}{l}46(37.75- \\
57.5)\end{array}$ & N/A & Not Described & N/A \\
\hline $\begin{array}{l}\text { Esmolol/Infusion Dose } \\
(\mathrm{mcg} / \mathrm{kg})\end{array}$ & $500 / 75$ & N/A & Not Described & N/A \\
\hline
\end{tabular}




\section{Quantitative Data Synthesis}

Both retrieved studies reported on the primary outcome of survival to hospital admission, as well as the secondary outcome of return of spontaneous circulation (ROSC). However, ROSC was delineated by both studies into temporary (greater than 30 seconds but less than 20 minutes) and sustained ROSC (over 20 minutes). Patient survival beyond hospital admission and neurological status post-SCA were assessed in both studies but at differing time points. Driver et al assessed patient survival and neurological status at the time of hospital discharge (44); however, Lee et al measured these outcomes at 30 days, three months and six months post-SCA (45). The authors of both studies were contacted in an attempt to amalgamate the raw patient data from both studies into an identical time point, however, the data was either unavailable or no response was received. Given that in Lee et al both survival and favourable neurological outcome remained unchanged between the three time points (45), these were used as an indicator of status at hospital discharge in an attempt to assess the potential effect of esmolol on long-term survival and neurological function post-SCA.

The results of quantitative data synthesis are shown in Figure 2. Esmolol was seen to provide a benefit when compared against standard ACLS care in the primary outcome of survival to hospital admission (RR 2.63, 95\% CI 1.37-5.07, $\mathrm{p}=0.004)$, as well as in the secondary outcomes of temporary (RR 2.34, 95\% CI 1.09-5.02, $\mathrm{p}=0.03$ ) and sustained ROSC (RR 2.63, 95\% CI 1.37-5.07, $\mathrm{p}=0.004)$ and favourable neurological status at hospital discharge (RR 3.44, 95\% CI 1.11-10.67, p=0.03). The use of esmolol appeared to likely confer benefit in survival to hospital discharge (RR 2.82, 95\% CI 1.01-7.93, p=0.05). It should be noted that in Driver et al, the only outcome measure reaching statistical significance was favourable neurological outcome at hospital discharge (RR 4.75, 95\% CI 1.02-22.06, p=0.04) (44). Significant heterogeneity was observed in the computation of temporary ROSC, with otherwise no heterogeneity observed. Without access to raw patient data, no subgroup analyses were performed. 
Figure 3: Forest Plot of Outcome Measures

\begin{tabular}{|c|c|c|c|c|c|c|c|c|c|c|c|}
\hline & Study or Subgroup & $\begin{array}{c}\text { Esmol } \\
\text { Events }\end{array}$ & $\begin{array}{l}\text { Iol } \\
\text { Total }\end{array}$ & $\begin{array}{l}\text { No Esm } \\
\text { Events }\end{array}$ & $\begin{array}{l}\text { holol } \\
\text { Total }\end{array}$ & Weight & $\begin{array}{c}\text { Risk Ratio } \\
\text { M-H, Random, } 95 \% \mathrm{Cl}\end{array}$ & & $\begin{array}{r}\text { Risk } \\
\text { M-H, Rand }\end{array}$ & $\begin{array}{l}\text { Ratio } \\
\text { lom, } 95 \% \mathrm{Cl}\end{array}$ & \\
\hline & Driver et al 2014 & 4 & 6 & 6 & 19 & $56.7 \%$ & $2.11[0.88,5.04]$ & & & & \\
\hline & Lee et al 2016 & 9 & 16 & 4 & 25 & $43.3 \%$ & $3.52[1.30,9.53]$ & & & & \\
\hline a & Total $(95 \% \mathrm{Cl})$ & & 22 & & 44 & $100.0 \%$ & $2.63[1.37,5.07]$ & & & & \\
\hline & Total events & 13 & & 10 & & & & & & & \\
\hline & $\begin{array}{l}\text { Heterogeneity. Tau }{ }^{2}= \\
\text { Test for overall effect: }\end{array}$ & $\begin{array}{l}0.00 ; \mathrm{Ch} \\
z=2.89\end{array}$ & $\begin{array}{l}i^{2}=0 \\
(P=0\end{array}$ & $\begin{array}{l}62, \mathrm{df}= \\
0.004 \mathrm{j}\end{array}$ & $1(P=$ & $0.43 \mathrm{~J} ; 1^{2}$ & $=0 \%$ & 0.01 & $\begin{array}{l}0.1 \\
\text { Favours ACLS }\end{array}$ & $\begin{array}{cc}1 & 10 \\
\text { Favours Esmolol }\end{array}$ & 100 \\
\hline & Study or Subgroup & $\begin{array}{r}\text { Esmo } \\
\text { Events }\end{array}$ & $\begin{array}{l}\text { lol } \\
\text { Total }\end{array}$ & $\begin{array}{l}\text { No Esm } \\
\text { Events }\end{array}$ & $\begin{array}{l}\text { nolol } \\
\text { Total }\end{array}$ & Weight & $\begin{array}{c}\text { Risk Ratio } \\
\mathrm{M}-\mathrm{H}, \text { Random, } 95 \% \mathrm{Cl}\end{array}$ & & $\begin{array}{r}\text { Risk } \\
M-H, \text { Rand }\end{array}$ & $\begin{array}{l}\text { Ratio } \\
\text { lom, } 95 \% \mathrm{Cl}\end{array}$ & \\
\hline & Driver et al 2014 & 4 & 6 & 6 & 19 & $56.7 \%$ & $2.11[0.88,5.04]$ & & & & \\
\hline & Lee et al 2016 & 9 & 16 & 4 & 25 & $43.3 \%$ & $3.52[1.30,9.53]$ & & & & \\
\hline & Total $(95 \% \mathrm{Cl})$ & & 22 & & 44 & $100.0 \%$ & $2.63[1.37,5.07]$ & & & & \\
\hline & Total events & 13 & & 10 & & & & & & & \\
\hline & $\begin{array}{l}\text { Heterogeneity. } \mathrm{Tau}^{2}= \\
\text { Test for overall effect: }\end{array}$ & $\begin{array}{l}=0.00 ; \mathrm{Ch} \\
\mathrm{z}=2.89\end{array}$ & $\begin{array}{l}h^{2}=0 \\
9(P=0\end{array}$ & $\begin{array}{l}62, \mathrm{df}= \\
0.0041\end{array}$ & $1(P=$ & $0.43 \mathrm{j} ; 1^{2}$ & $=0 \%$ & 0.01 & $\begin{array}{l}0.1 \\
\text { Favours ACLS }\end{array}$ & 1 Favours Esmolol & 100 \\
\hline & Study or Subgroup & $\begin{array}{l}\text { Esmol } \\
\text { Events }\end{array}$ & $\begin{array}{l}\text { lol } \\
\text { Total }\end{array}$ & $\begin{array}{l}\text { No Esm } \\
\text { Events }\end{array}$ & $\begin{array}{l}\text { 1olol } \\
\text { Total }\end{array}$ & Weight & $\begin{array}{c}\text { Risk Ratio } \\
\text { M-H, Random, } 95 \% \mathrm{Cl}\end{array}$ & & $\begin{array}{r}\text { Risk F } \\
\text { M-H, Rando }\end{array}$ & $\begin{array}{l}\text { Ratio } \\
\text { om, } 95 \% \mathrm{Cl}\end{array}$ & \\
\hline & Driver et al 2014 & 4 & 6 & 8 & 19 & $48.8 \%$ & $1.58[0.73,3.43]$ & & & $\square$ & \\
\hline & Lee et al 2016 & 13 & 16 & 6 & 25 & $51.2 \%$ & $3.39[1.62,7.07]$ & & & & \\
\hline & Total $(95 \% \mathrm{Cl})$ & & 22 & & 44 & $100.0 \%$ & $2.34[1.09,5.02]$ & & & & \\
\hline 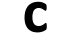 & Total events & 17 & & 14 & & & & & & & \\
\hline & $\begin{array}{l}\text { Heterogeneity. } \mathrm{Tau}^{2}= \\
\text { Test for overall effect: }\end{array}$ & $\begin{array}{l}=0.16 ; C h \\
z=2.18\end{array}$ & $\begin{array}{l}\mathrm{i}^{2}=2 \\
3(\mathrm{P}=0\end{array}$ & $\begin{array}{l}05, \mathrm{df}= \\
0.031\end{array}$ & $1(P=$ & $0.15 \mathrm{j} ; \mathrm{l}^{2}$ & $=51 \%$ & 0.01 & $\begin{array}{l}1 \\
0.1 \\
\text { Favours ACLS }\end{array}$ & $\begin{array}{c}10 \\
\text { Favours Esmolol }\end{array}$ & 100 \\
\hline & & Esmol & & No Esm & & & Risk Ratio & & Risk F & Ratio & \\
\hline & Study or Subgroup & Events & Total & Events & Total & Weight & M-H, Random, $95 \% \mathrm{Cl}$ & & M-H, Rando & $\% \mathrm{Cl}$ & \\
\hline & Driver et al 2014 & 3 & 6 & 3 & 19 & $62.0 \%$ & $3.17[0.85,11.75]$ & & & & \\
\hline & Lee et al 2016 & 3 & 16 & 2 & 25 & $38.0 \%$ & $2.34[0.44,12.52]$ & & & & \\
\hline & Total $(95 \% \mathrm{Cl})$ & & 22 & & 44 & $100.0 \%$ & $2.82[1.01,7.93]$ & & & & \\
\hline & Total events & 6 & & 5 & & & & & & & \\
\hline & $\begin{array}{l}\text { Heterogeneity. } \mathrm{Tau}^{2}= \\
\text { Test for overall effect: }\end{array}$ & $\begin{array}{l}0.00 ; C h \\
z=1.97\end{array}$ & $\begin{array}{l}\mathrm{i}^{2}=0 \\
\mathrm{P}(\mathrm{P}=0\end{array}$ & $\begin{array}{l}08, \mathrm{df}= \\
0.051\end{array}$ & $1(P=$ & $0.78 \mathrm{j} ; 1^{2}$ & $=0 \%$ & 0.01 & 0.1 Favours ACLS & $\begin{array}{c}10 \\
\text { Favours Esmolol }\end{array}$ & 100 \\
\hline & & Esmol & lol & No Esm & nolol & & Risk Ratio & & Risk F & Ratio & \\
\hline & Study or Subgroup & Events & Total & Events & Total & Weight & $\mathrm{M}-\mathrm{H}$, Random, $95 \% \mathrm{CI}$ & & $\mathrm{M}-\mathrm{H}$, Rando & om, $95 \% \mathrm{Cl}$ & \\
\hline & Driver et al 2014 & 3 & 6 & 2 & 19 & $54.3 \%$ & $4.75[1.02,22.06]$ & & & a & \\
\hline & Lee et al 2016 & 3 & 16 & 2 & 25 & $45.7 \%$ & $2.34[0.44,12.52]$ & & & & \\
\hline $\mathbf{e}$ & Total $(95 \% \mathrm{Cl})$ & & 22 & & 44 & $100.0 \%$ & $3.44[1.11,10.67]$ & & & & \\
\hline & Total events & 6 & & 4 & & & & & & & \\
\hline & $\begin{array}{l}\text { Heterogeneity. } \mathrm{Tau}^{2}= \\
\text { Test for overall effect: }\end{array}$ & $\begin{array}{l}0.00 ; C h \\
z=2.14\end{array}$ & $\begin{array}{l}\text { hit }=0 \\
4(P=0\end{array}$ & $\begin{array}{l}38, \mathrm{df}= \\
0.031\end{array}$ & $1(P=$ & $0.54 \mathrm{j} ; \mathrm{I}^{2}$ & $=0 \%$ & 0.01 & $\begin{array}{l}1 \\
0.1 \\
\text { Favours ACLS }\end{array}$ & $\begin{array}{cc}1 & 1 \\
10 \\
\text { Favours Esmolol }\end{array}$ & 100 \\
\hline
\end{tabular}

\section{Quality Assessment and Risk of Bias (Supplementary File)}

a) Survival to Hospital Admission b) Sustained ROSC c) Temporary ROSC d) Survival to Hospital Discharge e) Favourable Neurological Status at Hospital Discharge

Both retrieved studies were considered to be of moderate methodological quality and at a significant risk of bias. It is unclear whether outcome assessors were blinded to treatment allocation in the assessment of ordinal variables. Whilst this was unlikely to influence the assessment of dichotomous outcomes (survival and ROSC), this could potentially influence the assessment of CPC score, with this methodological flaw placing both authors at moderate risk in the measurement of outcomes and detracting the level of 
confidence in the assessment of this outcome. In Driver et al (44), this was further compounded by the potential for inaccuracy in the measurement of outcomes, as the CPC score assessing neurological status was estimated based on notes from other clinicians at the time of hospital discharge. Four patients were excluded from the research performed by Driver et al (44) because of missing data, with the study subsequently considered at a moderate risk of bias because of this. The administration of esmolol in Driver et al (44) also appears to have been at physician discretion, leading to potential and likely significant sampling bias.

However, the assessment of both studies at significant risk of bias was primarily driven by the influence of confounding on the results obtained, which also affected the certainty of all outcome measures within the meta-analysis. Lee et al (45) failed to identify confounders present in their research, most notably premorbid state and post-ROSC therapies, which are both known predictors of patient status post-SCA (47, 48). Although Driver et al (44) did identify the majority of confounders potentially present in their research, however, neither group of authors modified the design of their research to minimise the influence of known or unknown confounders on the outcomes observed, with no multi-variate analyses performed $(44,45)$.

\section{GRADE Evaluation (Available in Supplementary Files)}

All outcomes were considered to suffer from significant imprecision, with wide confidence intervals reported. Significant heterogeneity was observed in the computation of temporary ROSC, leading to this result being considered of very low certainty. Considering the dichotomous outcomes were unlikely to be affected by knowledge of treatment group, these were considered only at serious risk of bias given the failure to account for residual confounders. However, because evaluation of CPC score may potentially be influenced by knowledge of treatment group, this result was considered of very low certainty. 


\section{Discussion}

A systematic review of the literature identified just two retrospective cohort studies examining the use of esmolol in rVF in human subjects. In completing a meta-analysis of the results from these studies, esmolol was found to improve patient survival to hospital admission, rates of temporary and sustained ROSC, favourable neurological status at hospital discharge and potentially survival to hospital discharge. However, it is important to interpret these results with a degree of caution, as the certainty in this evidence is of low to very low (49). No randomised, nor controlled, studies were identified, with both studies suffering from issues inherent in retrospective analyses including small sample sizes, methodological issues and significant risk of bias. Most concerning was the possible influence of confounding in both studies. Factors such as pre-morbid state, provision of bystander CC, length of SCA and timeliness of access to definitive care post-resuscitation have all been identified as influencing patient outcomes post-SCA (47). Although Driver et al (44) acknowledge the potential role these factors may have had on their outcomes, neither research group attempted to quantify the impact these factors may have had on outcomes in the design of their research or through the performance of multivariate analyses $(44,45)$, which ultimately affected the level of confidence within each outcome assessed.

Equally important to note is the potential role pre-hospital care and sampling bias played in the results obtained. In Driver et al, no difference was noted in total CC time between the intervention and control groups, despite a prolonged pre-hospital phase of care in the control group (44). This is consistent with the finding that patients who were expeditiously transported to the emergency department in rVF subsequently received prolonged resuscitative efforts in the emergency department, whilst those who arrived in the emergency department later in their SCA received shorter resuscitation times in the emergency department (44). Given that the administration of esmolol appears to have been at physician discretion it is possible patients with shorter pre-hospital phases of care received more aggressive 
Armour and Baranowski. Esmolol systematic review. https://doi.org/10.32378/ijp.v4i2.177

resuscitative measures, such as esmolol, as they were perceived to have better prognoses than those with protracted pre-hospital phases of care. This phenomenon was also observed by Lee et al (45), who found that patients with shorter pre-hospital phases of care experienced an improved likelihood of sustained ROSC ( $\mathrm{p}=0.02)$, despite similar total CC times between treatment and control groups. This, in itself, may result in this meta-analysis over-estimating the true benefit of esmolol in routine clinical practice as patients with perceived poorer prognoses may not have received esmolol based on this perception alone.

Lee et al (45) did not report on time taken to the administration of esmolol, however, the research performed by Driver et al (44) revealed substantial variability in the time taken to administration of esmolol. As previously stated, VF is considered refractory after at least three consecutive attempts at defibrillation and at least one dose of adrenaline or anti-arrhythmic therapy (18-20). Based on resuscitation guidelines, the earliest VF could be considered refractory is after six minutes of resuscitation, although in true clinical practice there may be a delay dependent on available resources. Despite this, the median time to administration of esmolol in Driver et al was 24 minutes after arrival in the emergency department (IQR 18.5-34), or 46 minutes after the initial SCA (IQR 37.7-57.5) (44). By this time, patients had already received a median of 6.5 attempts at defibrillation (IQR 4.75-10.75), indicating the administration of traditional therapy was prioritised over the administration of esmolol. This may also serve to mask the true benefit of esmolol, given the neurological damage associated with reduced cerebral perfusion pressures in prolonged resuscitation as well as the effect of increasing exogenous adrenaline administered throughout the resuscitative efforts which may hinder the antagonistic effects of esmolol.

Although the administration of a potentially life-saving medication, esmolol, in the setting of SCA and OHSCA could be considered low-risk, neither paper examined nor reported on adverse outcomes 
associated with the use of esmolol in rVF. In animal models, the use of intra-arrest esmolol for rVF was shown to have no deleterious effects on post-resuscitation cardiovascular stability $(37,38)$. However, the potential for adverse events from the antagonism of $\beta_{1}$-adrenoreceptors in the post-resuscitation patient cannot be discounted without a strong evidence base in humans. Institutions already employing the use of esmolol in the management of rVF should continue to be diligent in assessing for adverse effects secondary to the use of esmolol.

\section{Conclusion}

This systematic review and meta-analysis assessing the role of esmolol in the management of refractory ventricular fibrillation suggests that the use of esmolol is associated with improved survival to hospital admission, increased temporary and sustained ROSC and improved favourable neurological status at hospital discharge, and likely improved survival to hospital discharge. However, the conclusions of this meta-analysis are considerably limited by the significant risk of bias present in both studies, issues in methodological quality and small sample sizes as well as a lack of analysis regarding the safety of esmolol in the setting of cardiopulmonary arrest. With the strength of evidence of the retrieved results considered low to very low, high-quality, prospective research, preferably in the form of co-ordinated randomised controlled trials between pre-hospital and emergency clinicians, is urgently needed to assess the true impact of esmolol in the setting of refractory ventricular fibrillation before esmolol can be recommended for use in routine clinical practice. 
Armour and Baranowski. Esmolol systematic review. https://doi.org/10.32378/ijp.v4i2.177

\section{References}

1. Myerburg, R. Sudden Cardiac Death: Interface Between Pathophysiology and Epidemiology. Cardiac Electrophysiology Clinics (Online). 2017;9(4):515-524 DOI: 10.1016/j.ccep.2017.07.003

2. Hayashi, M. Shimzu, W. \& Albert, C. The Spectrum of Epidemiology Underlying Sudden Cardiac Death. Circulation Research (Online). 2015;116(12):1887-1906 DOI:

10.1161/CIRCRESAHA.116.304521

3. van Diepen, S. Girotra, S. Abella, B. Becker, L. Bobrow, B. Chan, P. Fahrenbruch, C. Granger, C. Jollis, K. McNally, B. White, L. Yannopoulos, D. \& Rea, T. Multistate 5-Year Initiative to Improve Care for Out-of-Hospital Cardiac Arrest: Primary Results from the HeartRescure Project. Journal of the American Heart Association (Online). 2017;6(9):e005716 DOI: 10.1161/JAHA.117.005716

4. Perkins, G. \& Brace-McDonnel, S. The UK Out-of-Hospital Cardiac Arrest Outcome (OHCAO) Project. BMJ Open (Online). 2015;5(10) DOI: 10.1136/bmjopen-2015-008736

5. Gardner, M. Leather, R. \& Teo, K. Chapter 1: Epidemiology. Prevention of Sudden Cardiac Death from Ventricular Arrhythmia. Canadian Cardiovascular Society (Online). 1999. Available from: http://ccs.ca/Guidelines_library/1999_Prevention_ventricular_arrhythmia-1.pdf

6. Beck, B. Bray, J. Smith, K. Walker, T. Grantham, H. Hein, C. Thorrowgood, M. Smith, A. Inoue, M. Smith, T. Dicker, B. Swain, A. Bosley, E. Pemberton, K. McKay, M. Johnston-Leek, M. Cameron, P. Perkins, G. Nichol, G. \& Finn, J. Epidemiology of Out-of-Hospital Cardiac Arrest (OHCA) in Australia and New Zealand: Results from the Aus-ROC OHCA Epistry. Resuscitation (Online). 2017;118(Supplement 1):e23 DOI: 10.1016/j.resuscitation.2017.08.065

7. Benjamin, E. Virani, S. Callaway, C. Chamberlain, A. Chang, A. Cheng, S. Chiuve, S. Cushman, M. Delling, F. Deo, R. de Ferranti, S. Ferguson, J. Fornage, M. Gillespie, C. Isasi, C. Jimenez, M. Jordan, L. Judd, S. Lackland, D. Lichtman, J. Lisabeth, L. Liu, S. Longenecker, C. Lutsey, P. Mackey, J. Machar, D. Matsushita, K. Mussolino, M. Nasr, K. O’Flaherty, M. Palaniappan, L. Pandey, A. Pandey, D. Reeves, M. Ritchey, M. Rodriquez, C. Roth, G. Rosamond, W. Sampson, U. 
Armour and Baranowski. Esmolol systematic review. https://doi.org/10.32378/ijp.v4i2.177

Satou, G. Shah, S. Spartano, N. Tirschwell, D. Tsao, C. Voeks, J. Willey, J. Wilkins, J. Wu, H. Alger, H. Wong, S. \& Muntner, P. Heart Disease and Stroke Statistics - 2018 Update: A Report from the American Heart Association. Circulation (Online). 2018;137(12):e67-e492

8. Park, G. Song, K. Shin, S. Lee, K. Ahn, K. Lee, E. Hong, K. \& Ro, Y. Timely Bystander CPR Improves Outcomes Despite Longer EMS Times. American Journal of Emergency Medicine (Online). 2017;35(8):1049-1055 DOI: 10.1016/j.ajem.2017.02.033

9. Riddersholm, S. Kragholm, K. Mortensen, R. Pape, M. Hansen, C. Lippert, F. Torp-Pedersen, S. Christiansen, C. \& Rasmussen, B. Association of Bystander Interventions and Hospital Length of Stay and Admission to Intensive Care Unit in Out-of-Hospital Cardiac Arrest Survivors. Resuscitation (Online). 2017;119:99-106 DOI: 10.1016/j.resuscitation.2017.07.014

10. Rajan, S. Wissenberg, M. Folke, F. Hansen, S. Gerds, T. Kragholm, K. Hansen, C. Karlsson, L. Lippert, F. Kober, L. Gislason, G. \& Torp-Pedersen, C. Association of Bystander Cardiopulmonary Resuscitation and Survival According to Ambulance Response Times After Out-of-Hospital Cardiac Arrest. Circulation (Online). 2016;134(25):2095-2104 DOI:

10.1161/CIRCULATIONAHA.116.024400

11. Benger, J. Kirby, K. Black, S. Brett, S. Clout, M. Lazaroo, M. Nolan, J. Reeves, B. Robinson, M. Scott, L. Smartt, H. South, A. Stokes, E. Taylor, J. Thomas, M. Voss, S. Wordsworth, S. \& Rogers, C. Effect of a Strategy of a Supraglottic Airway Device vs Tracheal Intubation During Out-ofHospital Cardiac Arrest on Functional Outcome. Journal of the American Medical Association (Online). 2018;320(8):779-791 DOI: 10.1001/jama.2018.11597

12. Perkins, G. Ji, C. Deakin, C. Quinn, T. Nolan, J. Scomparin, C. Regan, S. Long, J. Slowther, A. Pocock, H. Black, J. Moore, F. Fothergill, R. Rees, N. O’Shea, L. Docherty, M. Gunson, I. Han, K. Charlton, K. Finn, J. Petrou, S. Stallard, N. Gates, S. \& Lall, R. A Randomised Trial of Epinephrine in Out-of-Hospital Cardiac Arrest. New England Journal of Medicine (Online). 2018;379:711-721 DOI: 10.1056/NEJMoal806842 
Armour and Baranowski. Esmolol systematic review. https://doi.org/10.32378/ijp.v4i2.177

13. Kudenchuk, P. Brown, S. Daya, M. Rea, T. Nichol, G. Morrison, L. Leroux, B. Vaillancourt, C. Wittwer, L. Callaway, C. Christenson, J. Egan, D. Ornato, J. Weisfeldt, M. Stiell, I. Idris, A. Aufderheide, T. Dunford, J. Colella, R. Vilke, G. Brienza, A. Desvigne-Nickens, P. Gray, P. Gray, R. Seals, N. Straight, R. \& Dorian, P. Amiodarone, Lidocaine or Placebo in Out-of-Hospital Cardiac Arrest. New England Journal of Medicine (Online). 2016;374:1711-1722 DOI: 10.1056/NEJMoal1514204

14. Jabre, P. Penaloza, A. Pinero, D. Duchateau, F. Borron, S. Javaudin, F. Richard, O. de Longueville, D. Bouilleau, G. Devaud, M. Heidet, M. Lejeune, C. Fauroux, S. Greingor, J. Manara, A. Hubert, J. Guihard, B. Vermylen, O. Lievens, P. Auffret, Y. Maisondieu, C. Huet, S. Claessens, B. Lapostolle, F. Javaud, N. Reuter, P. Baker, E. Vicaut, E. \& Adnet, F. Effect of Bag-Mask Ventilation vs Endotracheal Intubation During Cardiopulmonary Resuscitation on Neurological Outcome After Outof-Hospital Cardiorespiratory Arrest. Journal of the American Medical Association (Online). 2018;319(8):779-787 DOI: 10.1001/jama.2018.0156

15. Jacobs, I. Finn, J. Jelinek, G. Oxer, H. \& Thompson, P. Effect of Adrenaline on Survival in Out-ofHospital Cardiac Arrest: A Randomised Double-Blind Placebo-Controlled Trial. Resuscitation (Online). 2011;82(9):1138-1143 DOI: 10.1016/j.resuscitation.2011.06.029

16. Holmberg, M. Holmberg, S. \& Herlitz, J. Incidence, Duration and Survival of Ventricular Fibrillation in Out-of-Hospital Cardiac Arrest Patients in Sweden. Resuscitation (Online). 2000;44(1):7-17 DOI: $10.1016 / \mathrm{S} 0300-9572(99) 00155-0$

17. Keller, S. \& Halperin, H. Cardiac Arrest: the Changing Incidence of Ventricular Fibrillation. Current Treatment Options in Cardiovascular Medicine (Online). 2015;17(7):392 DOI: 10.1007/s11936-0150392-z

18. Dorian, P. Cass, D. Schwartz, B. Cooper, R. Gelaznikas, R. \& Barr, A. Amiodarone as Compated with Lidocaine for Shock-Resistant Ventricular Fibrillation. New England Journal of Medicine (Online). 2002;346:884-890 DOI: 10.1056/NEJMoa013029 
Armour and Baranowski. Esmolol systematic review. https://doi.org/10.32378/ijp.v4i2.177

19. Bourque, D. Daoust, R. Huard, V. \& Charneux, M. $\beta$-Blockers for the Treatment of Cardiac Arrest from Ventricular Fibrillation? Resuscitation (Online). 2007;75(3):434-444 DOI:

10.1016/j.resuscitation.2007.05.013

20. Yannopoulos, D. Bartos, J. Martin, C. Raveendran, G. Missov, E. Conterato, M. Frascone, R. Trembley, A. Sipprell, K. John, R. George, S. Carlson, K. Brunsvold, M. Garcia, S. \& Aufderheide, T. Minnesota Resuscitation Consortium's Advanced Perfusion and Reperfusion Cardiac Life Support Strategy for Out-of-Hospital Refractory Ventricular Fibrillation. Journal of the American Heart Association (Online). 2016;5:e003732 DOI: 10.1161/JAHA.116.003732

21. Siao, F. Chiu, C. Chiu, C. Chen, Y. Chen, Y. Hsieh, Y. Lee, C. Wu, C. Chou, C. \& Yen, H. Managing Cardiac Arrest with Refractory Ventricular Fibrillation in the Emergency Department: Conventional Cardiopulmonary Resuscitation versus Extracorporeal Cardiopulmonary Resuscitation. Resuscitation (Online). 2015;92:70-76 DOI: 10.1016/j.resuscitation.2015.04.016

22. Hira, R. \& Nichol, G. Management of Refractory Ventricular Fibrillation: Extracorporeal Membrane Oxygenation or Epinephrine? Journal of the American College of Cardiology (Online). 2017;2(3) DOI: $10.1016 /$ j.jacbts.2017.04.001

23. Surawicz, B. Ventricular Fibrillation. Journal of the American College of Cardiology (Online). 1985;5(6):43B-54B DOI: 10.1016/S0735-1097(85)80526-X

24. Luqman, N. Sung, R. Wang, C. \& Kuo, C. Myocardial Ischemia and Ventricular Fibrillation: Pathophysiology and Clinical Implications. International Journal of Cardiology (Online). 2007;119(3):283-290 DOI: 10.1016/j.ijcard.2006.09.016

25. Tang, W. Weil, M. Gazmuri, R. Duggal, C. \& Bisera, J. Pulmonary Ventilation/Perfusion Defects Induced by Epinephrine During Cardiopulmonary Resuscitation. Circulation (Online). 1991;84(5):2101-2107 DOI: 10.1161.01.CIR.84.5.2101

26. Hilwig, R. Kern, K. Berg, R. Sanders, A. Otto, C. \& Ewy, G. Catecholamines in Cardiac Arrest: Role of Alpha Agonists, Beta-Adrenergic Blockers and High-Dose Epinephrine. Resuscitation (Online). 2000;47(2):203-208 DOI: 10.1016/S0300-9572(00)00261-6 
Armour and Baranowski. Esmolol systematic review. https://doi.org/10.32378/ijp.v4i2.177

27. Eschenhagen, T. Is Ryanodine Receptor Phosphorylation Key to the Fight or Flight Response and Heart Failure? The Journal of Clinical Investigation (Online). 2010;120(12):4197-4203 DOI: 10.1172/JCI45251

28. Zaugg, C. Current Concepts on Ventricular Fibrillation: A vicious Circle of Cardiomyocyte Calcium Overload in the Initiation, Maintenance and Termination of Ventricular Fibrillation. Indian Pacing and Electrophysiology Journal (Online). 2004;4(2):85-92

29. Ross, E. Redman, T. Harper, S. Mapp, J. Wampler, D. \& Miramontes, D. Dual Defibrillation in Outof-Hospital Cardiac Arrest: A Retrospective Cohort Analysis. Resuscitation(Online). 2016;106:14-17 DOI: $10.1016 /$ j.resuscitation.2016.06.011

30. Hajjar, K. Berbari, I. El Tawil, C. Bou Chebl, R. \& Abou Dagher, G. Dual Defibrillation in Patients with Refractory Ventricular Fibrillation. American Journal of Emergency Medicine (Online). 2018;36(8):1474-1479 DOI: 10.1016/j.ajem.2018.04.060

31. Pourmand, A. Galvis, J. \& Yamane, D. The Controversial Role of Dual Sequential Defibrillation in Shockable Cardiac Arrest. American Journal of Emergency Medicine (Online). 2018;36(9):16741679 DOI: 10.1016/j.ajem.2018.05.078

32. Boehm, K. Keyes, D. Mader, L. \& Moccia, J. First Report of Survival in Refractory Ventricular Fibrillation after Dual-Axis Defibrillation and Esmolol Administration. Western Journal of Emergency Medicine (Online). 2016;17(6):762-765 DOI: 10.5811/westjem.2016.8.30351

33. de Oliveira, F. Feitosa-Filho, G. \& Ritt, L. Use of Beta-Blockers for the Treatment of Cardiac Arrest Due to Ventricular Fibrillation/Pulseless Ventricular Tachycardia: A Systematic Review. Resuscitation (Online). 2012;83(6):674-683 DOI: 10.1016/j.resuscitation.2012.01.025

34. Delorenzo, A. Nehme, Z. Yates, J. Bernard, S. \& Smith, K. Double Sequential External Defibrillation for Refractory Ventricular Fibrillation Out-of-Hospital Cardiac Arrest: A Systematic Review and Meta-Analysis. Resuscitation (Online). 2018:Article in Press. DOI:

10.1016/j.resuscitation.2018.10.025 
Armour and Baranowski. Esmolol systematic review. https://doi.org/10.32378/ijp.v4i2.177

35. Wiest, D. \& Haney, J. Clinical Pharmacokinetics and Therapeutic Efficacy of Esmolol. Clinical Pharmacokinetics (Online). 2012;51(6):347-356 DOI: 10.2165/11631590-000000000-00000

36. Tang, W. Weil, M. Sun, S. Noc, M. Yang, L. \& Gazmuri, R. Epinephrine Increases the Severity of Post-Resuscitation Myocardial Dysfunction. Circulation (Online). 1995;92:3089-3093 DOI: 10.1161/01.CIR.92.10.3089

37. Theochari, E. Xanthos, T. Papdimitriou, D. Demestiha, T. Condilis, N. Nikolaos, N. Tsiftsi, K. \& Papadimitriou, L. Selective Beta Blockade Improves the Outcome of Cardiopulmonary Resuscitation in a Swine Model of Cardiac Arrest. Annali Italiani di Chirurgia (Online). 2008;79(6):409-414

38. Killingsworth, C. Wei, C. Dell'Italia, L. Ardell, J. Kingsley, M. Smith, W. Ideker, R. \& Walcott, G. Short-Acting Beta-Adrenergic Antagonist Esmolol Given at Reperfusion Improves Survival After Prolonged Ventricular Fibrillation. Circulation (Online). 2004;109:2469-2474 DOI: 10.1161/01.CIR.0000128040.43933.D3

39. Reynolds, E. How are cerebral performance category scores measured for audit and research purposes? Resuscitation (Online). 2014;85(5):e73-e74. DOI: 10.1016/j.resuscitation.2014.01.011

40. Critical Appraisal Skills Program. CASP Systematic Review Checklist (Online). 2018. Available from: https://casp-uk.net/wp-content/uploads/2018/03/CASP-Systematic-Review-Checklist-2018_fillable$\underline{\text { form.pdf }}$

41. Critical Appraisal Skills Program. CASP Cohort Studies Checklist (Online). 2018. Available from: https://casp-uk.net/wp-content/uploads/2018/03/CASP-Cohort-Study-Checklist2018 fillable form.pdf

42. Moola, S. Munn, Z. Tufanaru, C. Aromataris, E. Sears, K. Sfetcu, R. Currie, M. Qureshi, R. Mattis, P. Lisy, K. \& Mu, P. Chapter 7: Systematic Reviews of Aetiology and Risk. Joanna Briggs Institute Reviewer's Manual (Online). The Joanna Briggs Institute. 2017. Available from: https://joannabriggs.org/sites/default/files/2019-05/JBI_Critical_AppraisalChecklist_for_Case_Control_Studies2017_0.pdf 
Armour and Baranowski. Esmolol systematic review. https://doi.org/10.32378/ijp.v4i2.177

43. Daya, M. Schmicker, R. Zive, D. Rea, T. Nichol, G. Buick, J. Brooks, S. Christenson, J. MacPhee, R. Craig, A. Rittenberger, J. Davis, D. May, S. Wigginton, J. \& Wang, H. Out-of-Hospital Cardiac Arrest Survival Improving Over Time: Results from the Resuscitation Outcomes Consortium (ROC). Resuscitation (Online). 2015;91:108-115 DOI: 10.1016/j.resuscitation.2015.02.003

44. Viera, A. Odds Ratios and Risk Ratios: What's the Difference and Why Does it Matter? Southern Medical Journal (Online). 2008;101(7):730-734 DOI: 10.1097/SMJ.0b013e31817a7ee4

45. Driver, B. Debaty, G. Plummer, D. \& Smith, S. Use of Esmolol after Failure of Standard Cardiopulmonary Resuscitation to Treat Patients with Refractory Ventricular Fibrillation. Resuscitation (Online). 2014;85(10):1337-1341 DOI: 10.1016/j.resuscitation.2014.06.032

46. Lee, Y. Lee, K. Min, Y. Ahn, H. Sohn, Y. Lee, W. Oh, Y. Cho, G. Seo, J. Shin, D. Park, S. \& Park, S. Refractory Ventricular Fibrillation Treated with Esmolol. Resuscitation (Online). 2016;107:150-155 DOI: $10.1016 /$ j.resuscitation.2016.07.243

47. Benjamin, E. Virani, S. Callaway, C. Chamberlain, A. Chang, A. Cheng, S. Chiuve, S. Cushman, M. Delling, F. Deo, R. de Ferranti, S. Ferguson, J. Fornage, M. Gillespie, C. Isasi, C. Jimenez, M. Jordan, L. Judd, S. Lackland, D. Lichtman, J. Lisabeth, L. Liu, S. Longenecker, C. Lutsey, P. Mackey, J. Matchar, D. Matsushita, K. Mussolino, M. Nasir, K. O’Flaherty, M. Palaniappan, L. Pandey, A. Pandey, D. Reeves, M. Ritchey, M. Rodriguez, C. Roth, G. Rosamond, W. Sampson, U. Satou, G. Shah, S. Spartano, N. Tirschwell, D. Tsao, C. Voeks, J. Willey, J. Wilkins, J. Wu, J. Alger, H. Wong, S. \& Munter, P. Heart and Stroke Statistics - 2018 Update: A Report from the American Heart Association. Circulation (Online). 2018;137:e67-e492 DOI: 10.1161/CIR.00000000000000558

48. Andrew, E. Nehme, Z. Bernard, S. \& Smith, K. The Influence of Comorbidity on Survival and LongTerm Outcomes after Out-of-Hospital Cardiac Arrest. Resuscitation (Online). 2017;110:42-47 DOI: 10.1016/j.resuscitation.2016.10.018

49. Peberdy, M. Callaway, C. Neumar, R. Geocadin, R. Zimmerman, J. Donnino, M. Gabrielli, A. Silvers, S. Zaritsky, A. Merchant, R. Vanden Hoek, T. \& Kronick, S. Post-Cardiac Arrest Care: 2010 American Heart Association Guidelines for Cardiopulmonary Resuscitation and Emergency 
Armour and Baranowski. Esmolol systematic review. https://doi.org/10.32378/ijp.v4i2.177

Cardiovascular Care. Circulation (Online). 2010;122:S768-S786 DOI:

10.1161/CIRCULATIONAHA.110.971002

50. Guyatt, G. Oxman, A. Vist, G. Kunz, R. Falck-Ytter, Y. Alonso-Coello, P. \& Schunemann, H.

GRADE: An Emerging Consensus on Rating Quality of Evidence and Strength of Recommendations.

British Medical Journal (Online). 2008;336:924 DOI: 10.1136/bmj.39489.470347.AD 